\title{
Research
}

\section{Management of Benign Parotid Lesions: An Overview of Complications and Extent of Surgical Resection}

\author{
Mohammed Jamil Hyder*, Salma Mohammed Al Sheibani, and Faisal Al Kalbani \\ Otolaryngology and Head \& Neck Surgery, Al Nahda Hospital, Muscat, Oman
}

${ }^{*}$ Correspondence to: Mohammed Jamil Hyder; Senior Consultant, Otolaryngology and Head \& Neck Surgery, Al Nahda Hospital, Muscat, Oman; Tel: +96899434413; E-mail: hyder@omantel.net.om

Received: Aug 24 $4^{\text {th }}$ 2020; Accepted: Sep $4^{\text {th }}, 2020$; Published: Sep $7^{\text {th }}, 2020$

Citation: Hyder MJ, Al-Sheibani SM, Al-Kalbani F. Management of benign parotid lesions: An overview of complications and extent of surgical resection. ENT Open A Open J. 2020; I(1): 4-8.

\begin{abstract}
Background

The surgical management of benign lesions of the parotid gland is focused on the complete removal of the lesion, minimizing the chances of recurrence and to preserve facial nerve function. There is a relative paucity of literature regarding the post-operative complications of the surgical procedures for benign parotid lesions. The aim of this study is to evaluate the post- operative complications of a limited surgical procedure, namely partial superficial parotidectomy.
\end{abstract}

\section{Material and Method}

This retrospective cohort study included all parotid surgeries performed for benign parotid pathology from January 2008 to December 2018 . The patient's demographic data, presenting symptoms, type of surgery performed, complications, presence of post operative facial nerve paralysis and grade, histopathology type and follow up period were collected from hospital records of Al Shifa system. The mean follow-up time was 12.5 months.

\section{Results}

The study yielded a total of 125 partial superficial parotidectomies performed on 123 patients with a mean age of 44.5 years (range 8-87 years). Pleomorphic adenoma $(n=68,54.4 \%)$ and Warthins tumor $(n=32,25.6 \%)$, were the most common neoplastic lesions. Non-neoplastic lesions were $18(14.4 \%)$. Temporary facial nerve weakness occurred in 11 patients $(8.8 \%)$. All cases of facial nerve weakness improved within three months post-operatively. The rate of salivary fistula and sialocele were $5.5 \%$ and $1.5 \%$ respectively. One patient who had histologically proven pleomorphic adenoma had recurrence of tumor $(0.8 \%)$.

\section{Conclusion}

Partial superficial parotidectomy was associated with low incidence of facial nerve dysfunction which was mostly transient, and no permanent facial nerve dysfunction was reported. Other complications like sialocele, salivary fistula and Frey's syndrome were reported at lower rates than the reported rates in the literature for the conventional superficial parotidectomy. The findings support partial superficial parotidectomy approach for the treatment of benign parotid pathology, which entails less extensive resection of parotid parenchyma and less extensive dissection of facial nerve branches thereby minimizing the risk of post-operative complications.

Keywords: Benign parotid lesions; Complications of parotid surgery; Facial nerve dysfunction; Partial superficial parotidectomy; Pleomorphic adenoma. 


\section{INTRODUCTION}

The most common benign neoplasm of the parotid gland is pleomorphic adenoma as it accounts for approximately $60 \%$ to $70 \%$ of all parotid neoplasms. ${ }^{1-4}$ It mainly affects the superficial portion of the parotid parenchyma. ${ }^{1-4}$ The surgical management of benign parotid neoplasm has remained a matter of debate and controversy. ${ }^{5}$ In the early twentieth century, fear of damage to facial nerve lead to the development of intra-capsular enucleation but the recurrence rate was up to $40 \%$, ${ }^{6}$ so superficial parotidectomy was popularized which involved identification and dissection of the main trunk and all branches of facial nerve and removal of parotid parenchyma lateral to the facial nerve along with the tumor within. This approach has reduced the recurrence rate to $5 \%{ }^{7}$ However, the procedure is sometimes associated with post- operative weakness of facial nerve, both temporary and permanent and with other complications such as salivary fistula, sialocele, Frey's syndrome and significant hollowing of facial contour at the parotid region. ${ }^{7-8}$ Subsequently less radical surgical techniques were introduced like partial superficial parotidectomy which entails removal of less parotid tissue and fewer branches of facial nerve were dissected thereby reducing the complications while recurrence rate remains similar. ${ }^{3}$ The surgical technique is even further refined to be less invasive and extra capsular dissection is practiced in which tumor is accessed directly, the tumor capsule is dissected out and only the branches of facial nerve directly in relation to the tumor are dissected and preserved. ${ }^{9,10}$

The incidence of complications after superficial parotidectomy is variable. Post-operative facial nerve weakness can affect up to $40 \%$ of patients although most is transient and recovers completely. ${ }^{11,12}$ In addition, the incidence of sialocele and salivary fistula was reported as $17 \%$ and $6 \%$ respectively ${ }^{13}$ and the incidence of Frey's syndrome have been reported in the range of 3 to $22 \% .{ }^{14}$

The authors offered partial superficial parotidectomy to the patients for the management of benign parotid lesions and the purpose of this study is to evaluate the outcome of this procedure in respect to post-operative complications like facial nerve dysfunction, hematoma, sialocele, salivary fistula, Frey's syndrome and recurrence. This will be helpful in providing data for patient information during pre-operative counseling and would further help to establish the credence of partial superficial parotidectomy procedure as a less invasive option for the management of benign parotid pathologies.

\section{MATERIAL AND METHOD}

This study is a retrospective cohort of all parotid surgeries performed for benign parotid pathology from January 2008 to December 2018. All the patients who underwent parotid surgery and histopathology confirmed a benign parotid pathology were included in the study. All patients who had pre-operative facial nerve dysfunction or parotid lesion had parapharyngeal space extension were excluded from the study. Fine needle aspiration cytology and CT Scan with contrast were done as standard pre-operative work up in the outpatient.

Demographic and clinical data were collected including age at the time of surgery, gender, smoking status, co-morbidities and length of follow up.

Approval was obtained from the hospital research and ethics committee for this retrospective analysis.

\section{SURGICALTECHNIQUE}

Three senior surgeons of the department performed the surgical procedures. A four channel continuous nerve monitoring device was used.

As standard procedure, modified Blair incision was used except in a few female patients, where one surgeon used a modified face lift incision with a posterior limb extending along the occipital hairline depending on tumor size. This procedure involves the following: a skin flap is raised underneath the Superficial Musculoaponeurotic System (SMAS) plane with adequate exposure of the operating field. The tympano-mastoid suture line is palpated and identified as the most definitive landmark for identification of the main trunk of the facial nerve. Only the branches of the facial nerve directly in relation to the tumor are dissected. Facial nerve branches unrelated to the lesion are not dissected. The tumor is removed with a cuff of $0.5 \mathrm{~cm}$ to $1 \mathrm{~cm}$ of normal parotid tissue wherever possible except for places where facial nerve branches directly abuts the tumor. After removal of tumor, the remaining portion of parotid gland and parotid fascia is approximated in order to reduce the resultant defect. A suction drain is placed and removed when the output is $10 \mathrm{ml}$ or less per 24 hours. Post-operatively, the patient is evaluated daily for facial nerve function status as per the House-Brackman (HB) grading system by different team of doctors every day until they are discharged. Facial nerve status and any other complication is documented.

The guidelines followed for definition of complications is listed in Table I.

Table I. Definition of Complications

\begin{tabular}{|l|l|}
\hline $\begin{array}{l}\text { 1. Facial Nerve dysfunc- } \\
\text { tion }{ }^{15,16}\end{array}$ & $\begin{array}{l}\text { Any facial nerve weakness after surgery } \\
\text {-Temporary: Any facial nerve dysfunction with full recov- } \\
\text { ery within 12 months. } \\
\text {-Permanent: Any facial nerve dysfunction which persist } \\
\text { over 12 months }\end{array}$ \\
\hline 2. Sialocele & $\begin{array}{l}\text { Persistent fluid collection at operation site needing treat- } \\
\text { ment }\end{array}$ \\
\hline 3. Salivary Fistula & $\begin{array}{l}\text { Salivary flow from the surgical site lasting for more than } \\
\text { two days }\end{array}$ \\
\hline 4. Frey's Syndrome 12 & $\begin{array}{l}\text { Gustatory sweating occurring within 12 months of surgery } \\
\text { leading to out- patient visit }\end{array}$ \\
\hline 5. Hematoma & Bleeding or collection of blood at the surgical site \\
\hline
\end{tabular}

The first follow up is scheduled after 2 weeks. In case of facial nerve dysfunction, the patient is reviewed every month until the facial nerve function recovers.

\section{RESULTS}

A total of 123 patients who underwent 125 parotidectomies from January 2008 to December 2018 were identified. Two patients had bilateral parotid surgeries. Two patients who were operated for schwannoma were excluded from the study because they had facial weakness preoperatively.

The mean follow-up duration ranged from 3 months to 95 months $($ mean $=12.5 \pm 14.0)$

The complications noted were facial nerve dysfunction, hemorrhage or hematoma, sialocele, salivary fistula and Frey's syndrome.

The majority of lesions were pleomorphic adenoma $(n=68$, $54.4 \%)$. Warthin's tumor was next common pathology $(n=32,25.6 \%)$ 
(Table II). The non-neoplastic lesions were 18 accounting for $14.4 \%$. The details of non-neoplastic lesions are given in Table III.

Table II. Neoplastic parotid lesions

\begin{tabular}{|c|c|}
\hline Lesion Type & Number of Cases \\
\hline Pleomorphic Adenoma & 68 \\
\hline Warthin's Tumour & 32 \\
\hline Basal Cell Adenoma & 5 \\
\hline Oncocytoma & 2 \\
\hline
\end{tabular}

Table III. Non-neoplastic Parotid lesions

\begin{tabular}{|c|c|}
\hline Lesion Type & Number of Cases \\
\hline Lymphoepithelial Cyst (HIV +ve) & 3 \\
\hline Lymphoepithelial Cyst & 2 \\
\hline Epidermal Cyst & 2 \\
\hline Lipoma & 3 \\
\hline Lymphoepithelial Sialadenitis & 1 \\
\hline Chronic Sialadenitis & 4 \\
\hline Chronic granulomatous Sialadenitis & 3 \\
\hline
\end{tabular}

The most frequent complication encountered is transient facial paralysis which was seen in 11 patients $(8.8 \%)$ as shown in Table IV.

Table IV. List of complications $(n=125)$

\begin{tabular}{|c|c|}
\hline Complications & N (\%) \\
\hline -Facial Nerve Dysfunction & $11(8.8 \%)$ \\
\hline -Sialocele & $2(1.6 \%)$ \\
\hline -Salivary Fistula & $7(5.5 \%)$ \\
\hline -Hemorrhage/ Hematoma & $2(1.6 \%)$ \\
\hline -Frey's Syndrome & $2(1.6 \%)$ \\
\hline
\end{tabular}

Facial paralysis recovered completely within 3 months postoperatively. The degree of facial nerve dysfunction as per $\mathrm{HB}$ facial nerve grading system was Grade II in 5 cases, grade III in 4 cases, and grade IV in 2 cases. Isolated marginal mandibular nerve involvement is encountered in 3 cases. We observed that almost all the patients who had transient facial nerve weakness recovered within two to four weeks except the two patients in grade IV weakness that were diabetic and took longer time to recover (Table V). The association between the histopathology and grade of facial nerve paralysis was not statistically significant ( $p$ value $=0.2$, Chi-square test was used).

Table V. Grading of facial nerve weakness and its relationship with histopathology

\begin{tabular}{|l|c|c|c|}
\hline Facial Nerve Dysfunction & \multicolumn{3}{|l|}{ n=11 } \\
\hline HB facial nerve Grading & Grade II & Grade III & Grade IV \\
\cline { 2 - 4 } & 5 & 4 & 2 \\
\hline Histopathology & 4 & 1 & \\
\hline Pleomorphic adenoma (n=5) & 1 & 2 & 1 \\
\hline Warthins (n=4) & & & 1 \\
\hline Keratinous cyst (n=1) & & 1 & \\
\hline Oncocytoma (n=1) & & & \\
\hline
\end{tabular}

The two patients who developed sialocele responded to conservative management with aspiration and pressure dressing. All salivary fistula cases $(n=7,5.5 \%)$ improved with pressure dressing and did not require any further intervention.
The two patients who developed hematoma post-operatively underwent surgical intervention. The two patients who developed Frey's Syndrome were managed with injection of botulinum toxin A. One of them had pleomorphic adenoma extending to deep lobe and the other patient had partial superficial parotidectomy for foreign body type granulomatous reaction. The list of encountered complications is shown in Table IV.

One of the 125 patients who had benign parotid tumors developed recurrence. He was a 23 years old male who had partial superficial parotidectomy for pleomorphic adenoma. Nothing significant was noted intra-operatively and there was no breach of capsule or spillage from the tumor. Recurrence was noted by the patient himself approximately one year after surgery when he was temporarily residing abroad. He underwent revision surgery there.

\section{DISCUSSION}

The parotid parenchyma lateral to the facial nerve accounts for almost $70 \%$ of the gland, only one third of parotid tissue lies deep to the facial nerve. ${ }^{17}$ Because most of the gland parenchyma is superficial to the facial nerve, $90 \%$ of the parotid tumors occur in the superficial lobe. ${ }^{8}$ Conventional superficial parotidectomy, which involves the removal of most of the superficial lobe, usually results in significant hollowing of the facial contour. The partial superficial parotidectomy usually offers better aesthetic outcomes with similar rate of success. ${ }^{3,5,8}$

Over the last few decades, like in other fields of surgery, parotid gland surgery is also moving towards less invasive surgical procedures with lesser tissue resection. We have attempted to analyze the results of partial superficial parotidectomy in the management of benign parotid lesions. The technique and advantages of partial superficial parotidectomy has been widely publicized in literature. . $^{3,4,10,16,18,19}$

In partial superficial parotidectomy the tumor is removed with a thin rim of normal parotid tissue, the resultant defect is small, and the remaining tissue can be put together so there is minimum deformity. ${ }^{3,8,20}$ Also, many surgeons believe that meticulous dissection of all branches of facial nerve increases the risk of intra-operative nerve damage and causes scarring in the area of the nerve which can make revision surgery for recurrence much more difficult and riskier. ${ }^{19,21,22}$

The selection criteria for partial superficial parotidectomy varies. ${ }^{19,23}$ We did not follow any specific criteria for selection, we just followed the concept that less extensive surgery results in fewer complications. ${ }^{24}$ Therefore, the decision for extent of surgery in our patients was also depended on the size of the tumor and the number of facial nerve branches involved. ${ }^{25,26}$

Facial nerve monitoring was used in all the performed cases, although it has been shown in a meta-analysis that its use does not reduce facial nerve damage but it may reduce the incidence of transient facial nerve weakness and we also found that it is helpful when there is significant pericapsular fibrosis and adhesions. ${ }^{15}$ In our series, transient facial dysfunction occurred in $8.8 \%$ of cases and all of them recovered completely within three months. If we compare the incidence of transient facial nerve dysfunction in conventional superficial parotidectomy where all branches of facial nerve are dissected and preserved ranges from 13.6 to $26 \%{ }^{27}$ whereas in partial superficial parotidectomy the incidence of transient facial nerve dysfunction ranges from $6.9 \%$ to $18 \% .{ }^{5}$ Also, no permanent facial nerve weakness occurred in our se- 
ries which is consistent with other studies. ${ }^{4}$ In a meta-analysis, historical data showed that the incidence of permanent dysfunction average was $1.9 \%$ with superficial parotidectomy and $0.2 \%$ with Partial superficial parotidectomy ${ }^{27}$ In three of our patients who developed transient facial nerve dysfunction, only marginal mandibular branch of facial nerve was involved. In other studies, marginal mandibular nerve is the main nerve involved in transient facial nerve weakness. ${ }^{16,28}$

We have described the extent of facial nerve dysfunction as per the House-Brackman facial nerve staging system. Out of 11 cases, in 9 cases, the stage of facial weakness was mild dysfunction (grade II and III). Only in two patients it was grade IV, interestingly both of them were diabetic. One of them had Warthins tumor and lot of fibrosis was encountered around the lesion. The other patient had keratinous cyst. The association between the histopathology and grade of facial nerve paralysis was not statistically significant.

Sialocele developed in two patients (1.6\%) and salivary fistula in 7 (5.6\%). Hematoma was recorded in two patients. In some studies, the incidence of sialocele is reported ranges from $5 \%$ to $17 \%$ and salivary fistula as $6 \%$ to $11 \%$, so our findings are lower with the incidence cited in other studies ${ }^{13,29}$ perhaps due to approximation of parotid fascia and the remining parotid parenchyma. The incidence of Frey's Syndrome is $1.6 \%$ in our series. This is based on subjective complain from the patients and minor's iodine test was not done in these patients. The reported incidence of Frey's syndrome in some studies is as high as $50 \% .{ }^{30}$ We think that limited removal of parotid tissue, approximation of parotid fascia after the excision and raising the flap in sub SMAS plane are the possible reasons for the low incidence of Frey's Syndrome. ${ }^{3,16,31,32}$

The recurrence rate of pleomorphic adenoma is dependent on the degree of surgical resection. It has been reported as high as $45 \%$ for enucleation. ${ }^{33}$ With superficial parotidectomy it has been reduced to 1 to 4 $\%{ }^{34} \mathrm{We}$ had one recurrence of pleomorphic adenoma in our study. In a meta-analysis, as per historic data, the rate of recurrence with superficial parotidectomy, partial superficial parotidectomy and extra capsular dissection on average was less than $3 \%{ }^{35}$

It is significant to note that among the non-neoplastic pathology in this study, three patients who had lymphoepithelial cyst were tested positive for retroviral infection post operatively. So, in all cystic lesion of parotid gland, the possibility of retroviral infection should be kept in mind along with other differential diagnosis. ${ }^{36,37}$

\section{CONCLUSION}

Partial superficial parotidectomy is a less invasive surgical procedure for the treatment of benign lesions of the parotid gland. It is associated with reduced incidence of transient facial nerve dysfunction and other complications including sialocele, salivary fistula and Frey's Syndrome. Partial superficial parotidectomy procedure offers a moderate approach in comparison to the extremes of superficial parotidectomy with complete removal of superficial lobe of parotid and extra-capsular dissection with minimum identification and dissection of facial nerve branches.

The incidence of complications found in this study would serve to assist the surgeons in pre- operative counseling of the patients and decision making.

\section{CONFLICTS OF INTEREST}

None.

\section{REFERENCES}

1. Spiro RH. Salivary neoplasms. Overview of a 35-year experience with 2807 patients. Head Neck Surg. 1986; 8(3): 177-184. doi: 10.1002/ hed.2890080309.

2. Mantsopoulos K, Koch M, Klintworth N, Zenk J, Iro H. Evolution and changing trends in surgery for benign parotid tumors. Laryngoscope. 2015; 125(1): 122-127. doi: 10.1002/lary.24837.

3. Papadogeorgakis N. Partial superficial parotidectomy as the method of choice for treating pleomorphic adenoma of parotid gland. $\mathrm{Br}$ J of Oral and Maxillofac Surg. 2011; 49(6): 447-450. doi: 10.1016/j. bjoms.2010.06.012

4. Lic, Mathies L, Hou X et al. A meta analysis of pros and cons of partial superficial parotidectomy versus superficial parotidectomy for the treatment of benign parotid neoplasms. Journal of Craniomaxillofac surg. 2020. doi: $10.1016 / \mathrm{j} / \mathrm{jcms} 2020.04 .002$.

5. Ahmet Erdem, Kilavuz Murat Sangu, Ercan, Pinar, et al. Superficial parotidectomy versus partial superficial parotidectomy: A comparison of complication rate, operative time and hospital stay. J Oral Maxillofac Surg . 2018; 76(9): 2027-2032. doi: 10.1016/j.joms.2018.04.001.

6. McFarland J. Mysterious mixed tumor of salivary glands. Surg Gynecol Obstet. 1943; 76: 23-34.

7. Bailey H. Parotidectomy: Indications and results. British Medical Journal. 1947; 1(4499): 404.

8. Yamashita T, Tomoda K, Kumazawa T. The usefulness of partial parotidectomy for benign parotid gland tumor: A retrospective study of 306 cases. Acta Otolaryngol Suppl. 1993; 500: 113-116. doi: $10.3109 / 00016489309126192$.

9. Albergotti WG, Nguyen SA, Zenk. Extra capsular dissection for benign parotid tumors: A meta-analysis. Laryngoscope. 2012; 122: 19541960. doi: 10.1002/lary.23396.

10. Witt RL, Retjo L. Pleomorphic adenoma: Extra capsular dissection versus partial superficial parotidectomy with facial nerve dissection. Delaware Medical Journal. 2209: 81(3): 119-125. doi: $10.1155 / 2014 / 564053$

11. Gaillard C, Perie S, Susini B, Jean Lacau St Guily. Facial nerve dysfunction after parotidectomy: The role of local factors. Laryngoscope. 2005; 115(2): 287-291. doi: 10.1097/01.mlg.0000154735.61775.cd.

12. Ruohoalho J, Makitie AA. Aro K, et al. Complications after surgery for benign parotid gland neoplasm: A prospective cohort study. Head Neck. 2017; 39(1):170-176. doi: 10.1002/hed.24496.

13. Tuckett J, Glynn R, Sheahan P. Impact of extent of parotid resection on post operative wound complications: A prospective study. Head Neck. 2015; 37(1): 64-68. doi: 10.1002/hed.23558.

14. Ogreden S1, Ruzgar S, Alimoglu Y, et al. Comparison of Freys syndrome rate following superficial parotidectomy and partial superficial parotidectomy for pleomorphic adenoma. Journal of craniofacial surgery. 2016; 27(5): e469-e471. doi: 10.1097/scs.0000000000002746.

15. Sood AJ, Houlton JJ, Nguyen SA, M Boyd Gillespie. Facial nerve monitoring during parotidectomy: A systematic review and metaanalysis. Otolaryngol Head Neck Surg. 2015; 152(4): 631-637. doi: $10.1177 / 0194599814568779$. 
16. Wong WK, Shetty S. The extent of surgery for benign parotid pathology and its influence on complications: A prospective cohort analysis. Am J Otolaryngol. 2018; 39(2): 162-166. doi: 10.1016/j.amjoto.2017.11.015.

17. Lavenstein H, Vanderwal JE, Tiwari RM, at al. Surgical management of 246 previously untreated pleomorphic adenomas of parotid gland. $\mathrm{Br}$ J Surg. 1997; 84(3): 399.

18. O' Brien CJ. Current management of benign parotid tumor -the role of limited superficial parotidectomy. Head and Neck. 2003; 25: 946-952.

19. Roh JL, Kim H, Park C. Randomized clinical trial comparing partial parotidectomy versus superficial or total parotidectomy. Br J of Surg. 2007; 94(9): 1081-1087. doi: 10.1002/bjs.5947.

20. Chua DYK, Goh CHK. Parotid gland surgery for benign tumors: have we come full circle? Proceedings of Singapore Health Care. 2014; 23(1): 53-56.

21. Renehan A, Gleave EN, McGurk M. An analysis of treatment of 114 patients with recurrent pleomorphic adenoma of parotid gland. Am J Surg.1996; 172(6): 710-714. doi: 10.1016/s0002-9610(96)00293-0.

22. George KS, McGurk M. Extra capsular dissection: Minimal resection for benign parotid tumor. Br J Oral Maxillofac Surg. 2011; 49(6): 451454. doi: 10.1016/j.bjoms.2010.10.005.

23. Zbaren P, Vvander Porteen, Witt RL, et al. Pleomorphic adenoma of the parotid: Formal parotidectomy or limited surgery? Am J of Surg. 2013; 205(1): 109-118. doi: 10.1016/j.amjsurg.2012.05.026.

24. Zhang S, Ma D, Guo C, et al. Conservation of salivary secretions and facial nerve function in partial superficial parotidectomy. Int J Oral Maxillofac Surg. 2013; 42(7): 868-873. doi: 10.1016/j.ijom.2013.03.014.

25. Quer M, Vander Parteen, Takes RP, et al. Surgical options in benign parotid tumor: A proposal for classification. Eur Arch Otolaryngol. 2017; 274(11): 1-12. doi: 10.1007/s00405-017-4650-4.

26. Stathopoulos P, Igoumenakis D, Smith WP. Partial, superficial and total parotidectomy in the management of benign parotid tumors. A 10 year prospective study of 205 patients. Journal of Oral and Maxillofacial Surgery. doi: 10.1016/j.joms.2017.06.018.

27. Witt RL. Significance of margin in parotid surgery for pleomorphic adenoma. Laryngoscope. 2002; 112(12): 2141-2154. doi:

\subsection{7/00005537-200212000-00004.}

28. Pedro Infante, Cassio, Eduardo Gonzalez, Alberto Garcia-PerlaGarcia, et al. Complications after superficial parotidectomy for pleomorphic adenoma. Med oral patol oral Cir Bucal. 2018; 23(4): 485-492. doi: 10.4317/medoral.22386

29. Nouraei SA, Ismail Y, Ferguson MS, et al. Analysis of complications following treatment of benign parotid disease. ANZ J Surg. 2008; 78(3): 134-138. doi: 10.1111/j.1445-2197.2007.04388.x.

30. Marchese-Ragona R, C De Filippis, G Marioni, A Staffieri. Treatment of complications of parotid gland surgery. Acta Otorhinolaryngol Ital. 2005; 25(3): 174-178.

31. Emodi O, El Naaj IA, Gordin A, et al. Superficial parotidectomy versus retrograde partial superficial parotidectomy in treating benign salivary gland tumor. J of Oral maxillofac Surg. 2010; 68(9): 2092-2098. doi: 10.1016/j.joms.2009.09.075.

32. Donovan DT, Conley JJ. Capsular significance in parotid tumor surgery: Reality and Myths of lateral lobectomy. Laryngoscope. 1984; 94(3): 324-329. doi: 10.1288/00005537-198403000-00006.

33. Makeieff, Marc, Pierfrancesco Pelliccia, Flavie Letois, Grégoire Mercier, Sebastien Arnaud et al. Recurrent Pleomorphic Adenoma: Results of Surgical Treatment. Ann Surg Oncol. 2010; 17(12): 3308-3313. doi: 10.1245/s10434-010-1173-2.

34. Riad MA, Abdel-Rahman H, Ezzat WF, Adly A, Dessouky O, Shehata M. Variables related to recurrence of pleomorphic adenomas: Outcome of parotid surgery in 182 cases. Laryngoscope. 2011; 121(7):14671472. doi: 10.1002/lary.21830.

35. Rea JL. Partial parotidectomies: Morbidity and benign tumor recurrence rate in a series of 94 patients. Laryngoscope. 2000; 110: 924-927. doi: 10.1097/00005537-200006000-00006.

36. Varnholt H, Thompson L, Pantanowiz L, Salivary gland lymphoepithelial cyst. Ear Nose and Throat J. 2007; 86(5): 265.

37. Naidoo M, Singh B, Ramdial PK, Moodley J, Allopi L. Lester B Lymphoepithelial lesion of parotid gland in HIV era- A south African experience. S Afr J Surg. 2007; 45(4): 136-138. 